\title{
KIT DE FERRAMENTAS DA QUALIDADE: ELABORAÇÃO DE PLANILHAS PRÁTICAS NO EXCEL PARA USO IMEDIATO
}

\author{
Cicera R. Janneally de S. Fernandes (UFCG) janneallyfernandes13@hotmail.com \\ Laiany E. Borges Rodrigues (UFCG) laianybr@gmail.com
}

\begin{abstract}
Resumo
Com o desenvolvimento acelerado do mercado de trabalho e produção, é possível notar carências em quesitos de gestão das empresas. Procurando cada vez mais manterem-se no mercado, que está muito competitivo, as organizações buscam meios que as fortaleça e impulsione-as mais adiante, mantendo-as firme em meio a esse mar de competitividade. Destacando a necessidade de atender sempre a voz dos clientes é necessário que o produto ofertado seja entregue com a maior qualidade possível sendo produzido com o menor custo para a empresa, para isso é preciso eliminar gargalos e desperdícios. É ai que a Gestão da Qualidade (GQ) entra e se torna bastante relevante para toda e qualquer organização, atuando nos mais diversificados setores controlando as causas e efeitos que os desperdícios podem gerar, tentando manter a produção a mais enxuta possível. As ferramentas da Qualidade possibilitam que o gestor ou órgão responsável pela produção identifique a causa raiz do problema e atue justamente tentando controlá-la e até mesmo eliminá-la, com isso consequentemente minimizará custos e desperdícios que possam vir a existir.
\end{abstract}

Palavras-Chaves: Gestão da Qualidade; Ferramentas da Qualidade; Desperdícios.

\section{Introdução}

A busca incessante pela Qualidade de produtos, serviços e atendimento têm crescido muito no decorrer dos anos e tende a aumentar cada vez mais, visto que as empresas tentam manterse e sobressair-se em função uma das outras. Ressaltando essa necessidade de obter uma qualidade em seus serviços ofertados, é necessário que a organização tenha e mantenha uma Gestão da Qualidade na empresa para controlar processos e evitar possíveis desperdícios no meio. Existem sete principais Ferramentas básicas da Qualidade a qual são dadas mais enfoque, que são Gráfico de Pareto, Diagrama de Ishikawa, Diagrama de Dispersão, Folha de Verificação, Histograma, Fluxograma e Carta de Controle. Salientando que, existem outras Ferramentas que dão suporte a GQ como, por exemplo, o 5W2H, 5 Porquês, Ciclo PDCA e Ciclo SDCA. Esses meios dão aos organizadores o poder de atuar diretamente na causa raiz do problema. Tendo em vista toda essa necessidade de produzir mais e cada vez melhor, foise então elaborada uma planilha por meio do Excel para auxiliar possíveis gestores a controlar seus processos, essas planilhas têm o objetivo de poupar tempo dos adeptos as Ferramentas da Qualidade, com uso prático e simples de entendimento, sendo preciso apenas que, o desfrutador do kit de ferramentas, realize somente o preenchimento das lacunas disponíveis para edição. Este presente estudo visa apresentar o desenvolvimento de um Kit de Ferramentas da Qualidade utilizando um editor de planilhas, produzido pela Microsoft, o Excel. 


\section{Referencial teórico}

Esta seção trata do referencial teórico nos termos associados a presente pesquisa. Assim, são apresentadas as várias definições sobre as Ferramentas da Qualidade e sua função na industrialização, relatando também a crescente utilização do método base de estudo.

\subsection{Gestão da qualidade}

"Conjunto de atividades coordenadas para dirigir e controlar uma organização com relação à qualidade, englobando o planejamento, o controle, a garantia e a melhoria da qualidade". (Carvalho et al, 2005).

A Gestão da Qualidade (GQ) pode ser compreendida e aceita como um dos métodos e conceitos mais importantes para qualquer tipo de organização. É uma estratégia de gerenciamento que possibilita acompanhar e fornecer um maior grau de qualidade a um serviço ou produto, tendo como objetivo minimizar desperdícios eliminando atividades que não agregam valor ao cliente final. Pode ainda ser considerada como um requisito básico e obrigatório às empresas, empresas essas que desejam manter-se competitiva e continuar ativas no mercado. A GQ possui características bastante relevantes e que se destacam pelo comprometimento para com a empresa e clientes, uma delas é a ânsia pela melhoria continua.

\subsection{Ferramentas da qualidade}

Ferramentas da qualidade tratam-se de ferramentas estatísticas que são implementadas, normalmente, em organizações e ajudam no controle da produção e processos.

Para um processo ter qualidade é necessário à aplicação de ferramentas básicas para controlar e planejar a qualidade (MARQUES, 2010). Para Aildefonso (2007), as ferramentas da qualidade têm como função: solução de problemas, aumentar a eficácia de processos produtivos, detectar problemas, descobrir causas, prioridade e soluções, auxiliar na avaliação e controle das medidas corretivas.

As 7 Ferramentas do Controle de Qualidade são: Fluxograma, Diagrama Ishikawa (Espinhade-Peixe), Folha de Verificação, Diagrama de Pareto, Histograma, Diagrama de Dispersão e Cartas de Controle. Estas sete ferramentas fazem parte de um grupo de métodos estatísticos primordiais, e é importante que todos os envolvidos na empresa tenham conhecimento de todo o processo e métodos utilizados para o controle dos mesmos e, por isso, devem fazer parte dos programas básicos de treinamentos das organizações.

Geralmente, esses métodos são por meio de gráficos e planilhas. Tais métodos permitem ao gestor que analise de forma mais rápida e visual a situação de cada operação podendo ainda atuar de forma mais eficaz na raiz do problema. É preciso ter em mente que não basta apenas ter todos os dados estatísticos explanados de maneira visual e organizada por meio das ferramentas da qualidade se não obtiver uma satisfação final do cliente, ou seja, é necessário que tal processo seja capaz de atender a demanda do mesmo.

\subsection{1 - Folha de verificação}

A Folha de Verificação é uma técnica bastante utilizada para coleta de dados em uma empresa, por proporcionar ao gestor, forma clara aos dados obtidos e fácil manuseio. Magalhães (2000) define folha de verificação como sendo formulários planejados que são 
preenchidos de forma fácil e sucinta os dados coletados. Com os dados dos itens registrados, permite ao gestor a facilidade de interpretar de forma imediata uma determinada situação, ajudando a diminuir erros e confusões. "Seu objetivo é acompanhar o processo de produção, analisando e coletando dados referentes ao problema (efeito) a ser analisado" (VIEIRA et al., 1999).

O objetivo da Folha de Verificação é que seja um método fácil de visualizar e preencher para que a analise final dos dados preenchidos ocorra de forma clara e precisa para o estudo dos itens verificados, possibilitando checar até mesmo causas e localização dos problemas relatados. Pode ser utilizado em diversas situações, tais como localizar itens defeituosos, localizar defeitos, falhas, verificar a frequência de situações, entre outros.

\subsection{2 - Carta de controle}

Ferramenta cuja finalidade é mostrar os pontos de observação em um período de tempo. Os limites de controle são calculados aplicando-se fórmulas simples aos dados do processo. As cartas de controle podem trabalhar tanto com dados por variável (mensuráveis) como com dados por atributo (discretos).

Em outras palavras, a carta de controle é um gráfico que mostra de forma visual e simplificada como está o processo, possui limites superior e inferior de controle e um limite médio, tais limites servem para a organização acompanhar o processo e verificar possíveis desníveis na operação, atuando de forma objetiva intervindo quando há sinais de que está fora de controle.

\subsection{3 - Fluxograma}

É uma ferramenta que utiliza símbolos de forma gráfica para apresentar de forma visual a sequência das atividades dos processos e a interação entre uma atividade e outra. Com essa ferramenta é possível observar melhor o processo, ajudando em seu entendimento e possibilitando tomar possíveis decisões dentro da organização.

O fluxograma é um tipo de diagrama que descreve em etapas o processo de produção de uma empresa, por exemplo. De acordo com Juliano M. Magalhães (2016) o fluxograma tem como finalidade identificar o caminho real e ideal para um produto ou serviço com o objetivo de identificar os desvios. É uma ilustração sequencial de todas as etapas de um processo, mostrando como cada etapa é relacionada. Utiliza símbolos facilmente reconhecidos para denotar os diferentes tipos de operações em um processo.

\subsection{4 - Diagrama de ishikawa}

No que se refere ao Diagrama de Causa e Efeito ou espinha de peixe proposto originalmente por Kaoru Ishikawa na década de 60, com o intuito de sintetizar as opiniões dos engenheiros quando estes discutiam sobre problemas de qualidade e também para explicar como vários fatores poderiam ser comuns entre si e estar relacionados (DANIEL, MURBACK, 2014; ALVES, PAULISTA, 2014).

O diagrama permite a organização das informações possibilitando a identificação das possíveis causas do problema, ele atua como um guia para a identificação da causa fundamental deste problema e é utilizado para sumarizar e apresentar possíveis causas do problema considerado, com isso, pode-se então, determinar medidas corretivas para serem adotadas (TRIVELLATO, 2010). 


\subsection{5 - Histograma}

Um Histograma é caracterizado com a função de mostrar a distribuição e comportamento dos dados através de um gráfico de barras que indica o número de unidade de cada categoria. É uma ferramenta muito importante para análises estatísticas da organização por mostrar dados de um processo que tem-se a pretensão de analisar o comportamento.

Pode-se medir por meio do Histograma grandezas físicas (peso, temperatura, pressão, volume, etc) e ocorrências no geral (numero de ligações por dia, de reclamações, de leads, etc). Através deste gráfico é possível identificar diversos fatores, entre eles estão amplitude e mediana.

\subsection{6 - Diagrama de dispersão}

O Diagrama de Dispersão descreve o que acontece com uma variável quando a outra muda, para testar possíveis relações de causa e efeito. Trata-se de uma representação gráfica que proporciona uma analise entre duas variáveis quantitativas. Pode ser utilizado para identificar causas de problemas e/ou avaliar ações positivas dentro da empresa, por exemplo.

\subsection{7 - Gráfico de pareto}

O gráfico de Pareto é um Gráfico de barras verticais que ordena as frequências das ocorrências de uma determinada característica a ser medida da maior para a menor, facilitando a priorização dos problemas, ele dispõe as informações de uma maneira que as torna clara e fácil de priorizar as ações (TRIVELLATO, 2010).

De acordo com Trivellato (2010), o gráfico de Pareto pode ser de dois tipos: para efeito que é o gráfico que ordena os problemas apresentados pela empresa de maneira que seja possível identificar o principal problema e para causas que ordena as causas de cada problema apresentado pela empresa.

Conhecido também como gráfico $80 / 20$ onde diz que $80 \%$ das conseqüências dentro de uma organização surge devido aos $20 \%$ das causas, onde busca priorizar apenas os problemas mais importantes visto que esses são muitas vezes mascarados pelos problemas pequenos ou sem importância.

\subsection{8 - 5W2H}

Behr et al. (2008, p. 39) define esta ferramenta como sendo "uma maneira de estruturarmos o pensamento de uma forma bem organizada e materializada antes de implantarmos alguma solução no negócio". A denominação deve-se ao uso de sete palavras em inglês: What (O que, qual), Where (onde), Who (quem), Why (porque, para que), When (quando), How (como) e How Much (quanto, custo). Esta ferramenta é amplamente utilizada devido à sua compreensão e facilidade de utilização.

$\mathrm{O} 5 \mathrm{~W} 2 \mathrm{H}$ ajuda a reduzir incertezas e aumentar a produtividade da organização, é uma ferramenta simples e prática e pode ser aplicada em diversas áreas da empresa, como por exemplo o planejamento e acompanhamento de atividades do dia a dia até o setor de planejamento estratégico e operacional do estabelecimento. 


\subsection{9 - 5 porquês}

É definido como uma ferramenta de caráter simples, sua principal atribuição está na resolução dos problemas que podem causar um grande impacto, atua diretamente na causa raiz, formula a pergunta "porque "cinco vezes para mapear e compreender o que aconteceu.

Também é conhecida como 5-Why e é intimamente ligada a melhoria contínua dentro de uma organização. Consiste na repetição da pergunta "por quê?" mediante o problema proposto a fim de obter respostas que levem o responsável pelo método a obter respostas simplificadas e de modo que chegue a causa raiz com clareza.

\subsubsection{0 - Ciclo PDCA e ciclo SDCA}

O ciclo PDCA, também conhecido como ciclo de Shewart ou ciclo de Deming, foi introduzido no Japão por Shewart e difundido por Deming em 1950. De acordo com Werkema (1995), esta ferramenta tem como principal finalidade tornar mais claros e objetivos os processos relacionados à gestão e visa assegurar a melhoria contínua destes. Esta metodologia é utilizada em diversas áreas de conhecimento; na Engenharia de Produção é amplamente aplicada na gestão da qualidade e planejamento estratégico, sendo utilizada como base das normas da família ISO, na resolução de problemas de Engenharia de diferentes naturezas e como orientação para tomada de decisão. Nesse sentido, Werkema (1995, p.24) 31 propõe que o "PDCA é um método gerencial de tomada de decisões para garantir o alcance das metas necessárias a sobrevivência de uma organização".

\section{Objetivos}

O objetivo da proposta de criação deste kit de ferramentas é justamente proporcionar ao operador um conjunto de ferramentas que permita que ele consiga chegar ao grau de eficiência/eficácia desejável em uma determinada atividade ou processo. Essas técnicas são necessárias para agradar o cliente, uma vez que na gestão de qualidade a preocupação não é apenas com a produção, mas com a qualidade do processo, produto e serviço.

As ferramentas da qualidade fazem parte do processo de implementação de programas de melhorias e a padronização de atividades, isso vem sendo cada vez mais importante para empresas que buscam excelência em seus negócios, com isso as empresas ganham em credibilidade, qualidade e consequentemente isso impacta diretamente, nas vendas, pois tendo todos os processos padronizados e corretos o tempo de entrega dos produtos, certamente será menor. Gerar um ambiente de trabalho adequado ao envolvimento pode trazer grandes vantagens à qualidade de produtos e/ou serviços.

Este é o principal intuito das ferramentas da qualidade, que priorizam a organização dos processos, bem como o aumento do nível de qualidade do que é oferecido aos clientes, identificando situações adversas no dia a dia empresarial, que podem impactar negativamente no produto final. No sentido de diminuir a ocorrência de tais problemas, as ferramentas aqui descritas foram elaboradas de forma dinâmica para ajudar os mais diversos tipos de negócios a melhorar continuamente e economizar tempo no quesito de sempre estar elaborando planilhas para o projeto, aqui se encontra 11 ferramentas para ajudar gestores no dia a dia.

\section{Metodologia}


Para realização do desenvolvimento do programa aqui abordado foi utilizado o editor de planilhas da Microsoft, autodenominado Excel.

Inicialmente realizou-se uma revisão bibliográfica sobre as ferramentas da qualidade mais utilizadas e que seria de interesse empregar no programa. Também foi feito um estudo para instruir-se sobre como realizar a composição do software. Depois de feita toda construção do software no Excel, realizou-se testes para se certificar se ele estava apto para o uso e aplicação e verificou-se que o aplicativo atua conforme idealizado.

\section{Elaboração do kit de ferramentas no excel}

O kit de ferramentas no Excel foi idealizado para que o usuário tivesse acesso a um programa que trouxesse o máximo de praticidade e simplicidade possível, oferecendo a possibilidade de se obter dessa forma, elementos que são capazes de auxiliá-lo na tomada de decisões, trazendo assim uma ampla satisfação a quem o utiliza.

A concepção do arranjo de ferramentas da qualidade no Excel foi feita da seguinte forma:

Inicialmente foi planejado todo o layout da plataforma para que tivesse uma interface o mais semelhante possível com um site, tento cores básicas como o preto, branco e laranja, e contendo no design abas com as funções como home, dicas, dúvidas, fale conosco e também as funções que dão acesso aos métodos da qualidade.

Logo após decidiu-se quais ferramentas seriam implantadas no software, determinando assim que se utilizaria as 7 ferramentas da qualidade ( Folha de verificação, Carta de controle, Ishikawa, Fluxograma, Gráfico de Pareto, Histograma, Diagrama de Dispersão), incluindo o 5W2H, 5-why e o SDCA. A escolha dessas ferramentas foi feita deste modo por se tratar dos métodos mais utilizados e porque eles se encaixam nas etapas do ciclo PDCA.

Depois de analisar o ciclo PDCA, foi observado que algumas ferramentas podem ser utilizadas em suas etapas, assim foi necessário um estudo mais profundo para identificar em quais etapas se inseria cada umas da ferramentas. O PDCA contém quatro etapas, e as ferramentas foram dividas em cada estágio da seguinte forma:

- PLAN (planejar) $\rightarrow$ Folha de verificação, Carta de Controle, Ishikawa, Fluxograma, Gráfico de Pareto, Histograma, 5 porquês, 5W2H e Diagrama de Dispersão.

- DO (executar) $\rightarrow 5 \mathrm{~W} 2 \mathrm{H}$

- CHECK (checar) $\rightarrow$ Folha de verificação

- ACT (agir) $\rightarrow$ SDCA 
A partir da sigla PDCA, que se encontra na página home, se tem acesso a todas as ferramentas e informações sobre cada etapa.

a) As ferramentas teóricas do PDCA e SDCA foram abordadas apenas de uma forma bem explicativa, onde o usuário terá acesso à informações sobre cada método e os significados de cada termo, tendo dessa forma noção de como efetuar aquela ferramenta, competindo a cada um responder as lacunas disponíveis com os dados requeridos.

b) A última etapa efetuada foram as comunicações, sendo observado inicialmente quais dados das ferramentas teriam ligação viu-se que o gráfico de Pareto, o diagrama de inspeção e o histograma poderiam se relacionar, pois apesar de ter visões diferentes seus gráficos possuem os mesmos dados, tratando do mesmo produto e faturamento. As demais ferramentas poderiam se relacionar, porém dependeria da forma como irá utilizá-las e do problema proposto.

c) As dicas e dúvidas foram adicionadas aos poucos, sendo acrescentadas informações relevantes que surgiram ao longo do desenvolvimento do programa. $\mathrm{Na}$ aba fale conosco se encontra informações como nome e email dos integrantes do grupo que elaborou o software.

Desse modo todo o programa foi concebido, sendo que a maior dificuldade foi na elaboração do gráfico de Pareto, diagrama de inspeção e o histograma, os demais trouxeram menos dificuldade ao serem desenvolvidos. Também foi necessário antes de toda a concepção estudar cada ferramenta individualmente para extrair o máximo de informações possíveis e assim aplicar na plataforma do programa.

\section{Resultados}

O término do programa teve um resultado eficiente, tendo em vista que é possível utilizar diversas ferramentas da qualidade em uma única plataforma tudo isso com uma funcionalidade prática e simples. 
Imagem 1: interface da aba home do kit básico de ferramentas

\section{kit básico de Ferramentas da Qualidade}

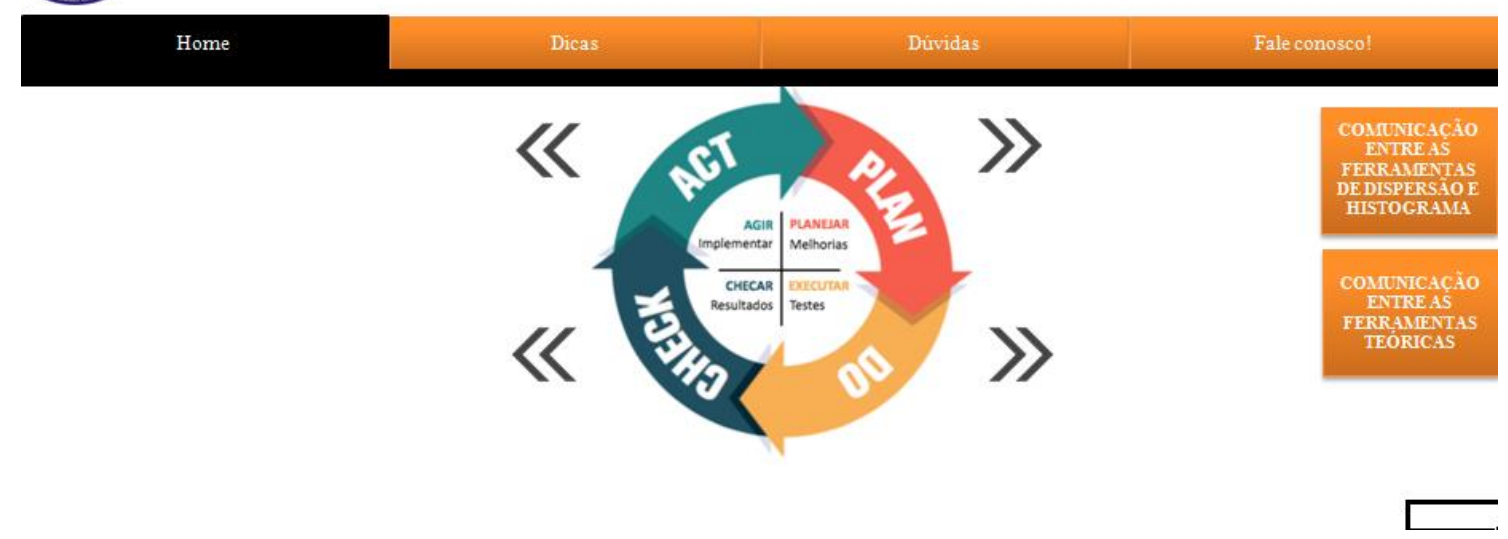

Fonte: Autoria própria

Na imagem 1 é possível ver que na aba home existe uma figura que remete a sigla do PDCA, cada parte da sigla corresponde a uma etapa do ciclo. Pode-se observar também na imagem que em cada etapa há uma seta que dá acesso a outra interface, onde estão todas as ferramentas que estão incluídas naquela etapa (ver figura 2, 3, 4 e 5). Para retornar para a aba home é só clicar novamente na seta.

Imagem 2: Ferramentas contidas na etapa de planejamento do PDCA

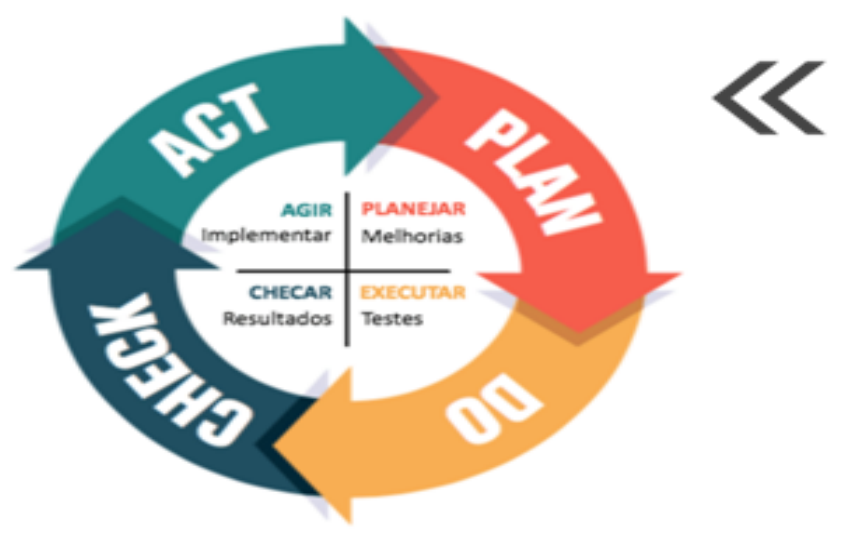

FOLHA DEVERIFICAÇÃO

CARTA DE CONTROLE

ISHIKAWA

FLUXOGRAMA

GRÁFICO DE PARETO

HISTOGRAMA

5 PORQUÊS

\section{$5 \mathrm{~W} 2 \mathrm{H}$}

DIAGRAMA DE DISPERSÃO

Fonte: autoria própria 
Figura 3: Ferramenta contida na etapa de executar do PDCA

Universidade Federa de Campina Grande kit básico de Ferramentas da Qualidade

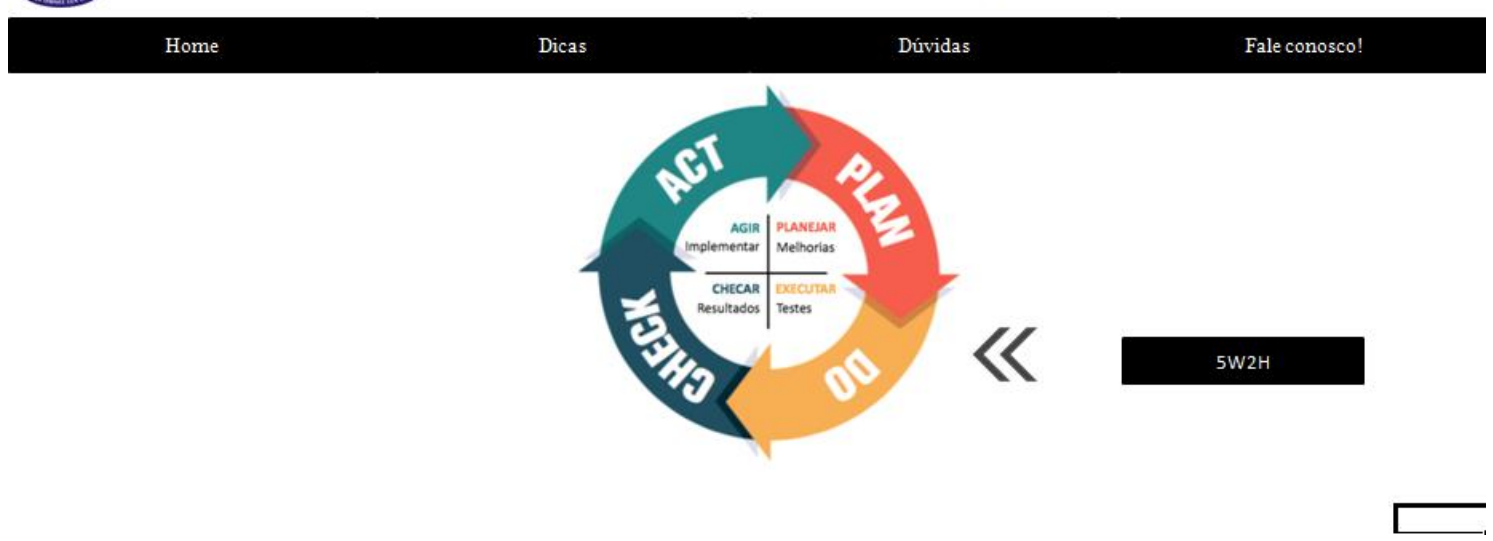

Fonte: Autoria própria

Figura 4: Ferramenta contida na etapa de checar do PDCA

\section{kit básico de Ferramentas da Qualidade}

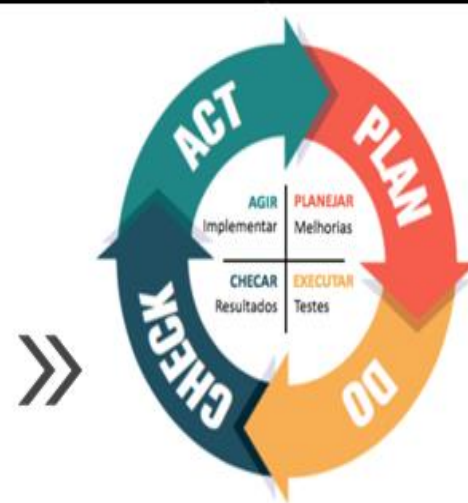

Fonte: Autoria própria 
Figura 5: Ferramenta contida na etapa de agir do PDCA

Universidade Federal

de Campina Grande

\section{kit básico de Ferramentas da Qualidade}

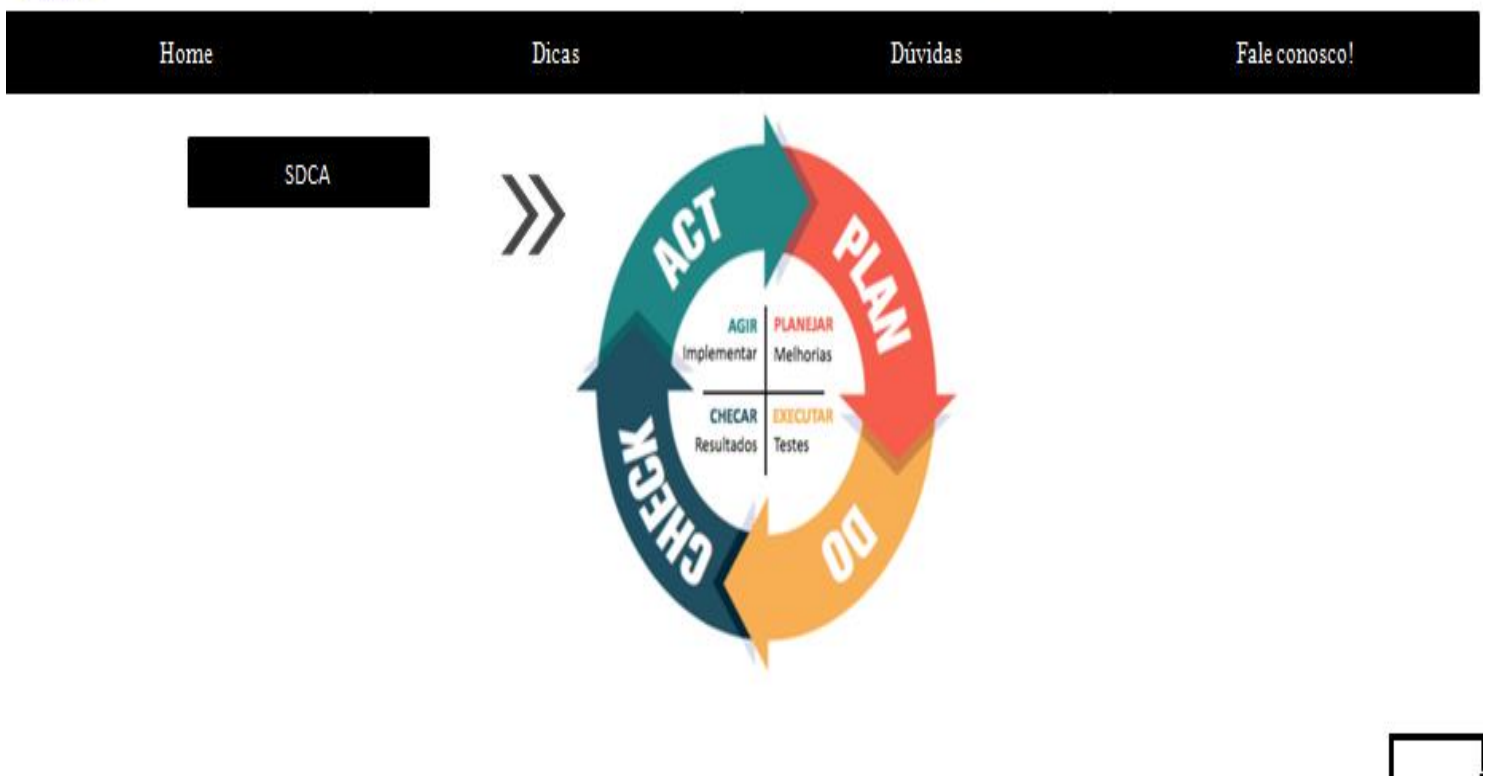

Fonte: Autoria própria

Figura 6: Aba dicas do kit básico de ferramentas da qualidade

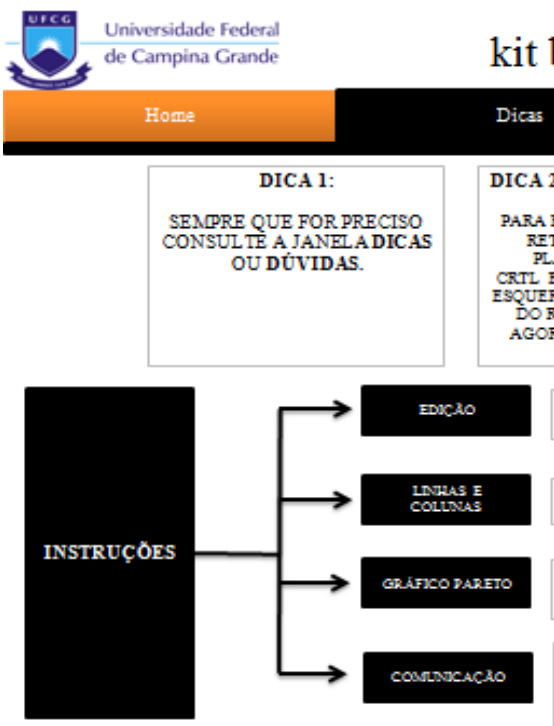
kit básico de Ferramentas da Qualidade

\begin{tabular}{|l|l|l|} 
Dicas & Duvidas & Fale conosco! \\
\hline
\end{tabular}

CA

PARA FDITAR OS TEXTOS DOS PETANGULOSDE CADA

CTLL E CLICAR COM O BOTÃ

CILDT DO MOUSE EM CDM

GORA APAGUE, OTEXTO E
DICA 3:

VERIFICAR SE 0 "FATURANENTO" DA TABELA DO GRAFICO DE ESTA COM O FIL TR PARA ORGANIZAR DO
DICA 4:

NA CARTA DE CONTROLE (CED) OS C, LV E LU ESTRO CONA VAL CORRESTONDENTE DA TABELA CSISC, LU EUC E DREEVCHD VRNGPUA

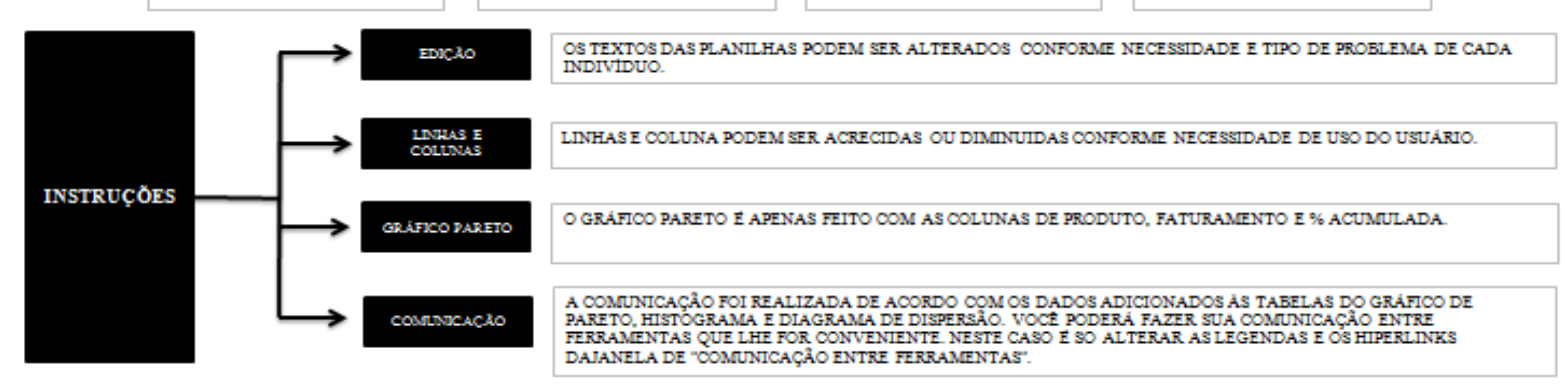

Fonte: autoria própria

A aba dicas contém instruções de como agir ao utilizar o programa, informando como é o funcionamento e auxiliando o usuário para que ele use as ferramentas da melhor forma possível sem nenhum contratempo. 
Figura 7: Aba dúvidas do kit básico de ferramentas da qualidade

\begin{tabular}{|c|c|c|}
\hline Home & Dicses & \\
\hline $\begin{array}{c}\text { DÚVIDA 1: } \\
\text { AS FERRAMENTAS "TEORICAS" } \\
\text { DO CICLO PDCA E SDCA AQUI } \\
\text { NO KIT FERRAMMNTAS DA } \\
\text { QUALIDADE E APENASO } \\
\text { SIGNIFICADO DE CADA TERMO. } \\
\text { CABE A VOCE TORNAR UM } \\
\text { CASO PRA ICO. }\end{array}$ & 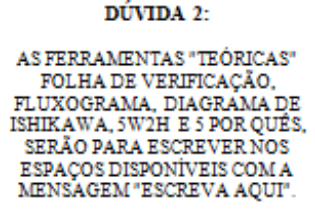 & $\begin{array}{r}\text { D } \\
\text { NÅO NOS R } \\
\text { PELO } \\
\text { FERRAMEN } \\
\text { FORAD } \\
\text { FACILITA } \\
\text { TEMPO D } \\
\text { FE. }\end{array}$ \\
\hline & $\begin{array}{r}\text { DÚVI } \\
\text { NASETAPASD } \\
\text { ESTA UNAA SU } \\
\text { PODE SERACES } \\
\text { DAS SEMNHAS } \\
\text { DE QUAL FERR } \\
\text { EMCAD. }\end{array}$ & $\begin{array}{l}\text { CLO PDCA } \\
\text { TAिO,QUE } \\
\text { A POR MEIO } \\
\text { ABA HOME. } \\
\text { NNAA USAR } \\
\text { APA. }\end{array}$ \\
\hline
\end{tabular}

DÚvidA 3:

ÅO NOS RESPONSABILIZANOS PELO MAL USO DAS RORANTAS, AS PLANILHAS FORAMCRIADAS PARA FCLIAR OUSO E POUPAR DOSUSUARIOSDA ERRANIENTA.

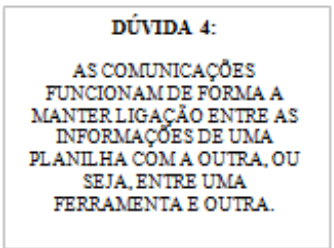

Fonte: Autoria própria

Essa aba contém algumas dúvidas que talvez surja quando o operador for utilizar o software.

Figura 8: Informações sobre o PDCA
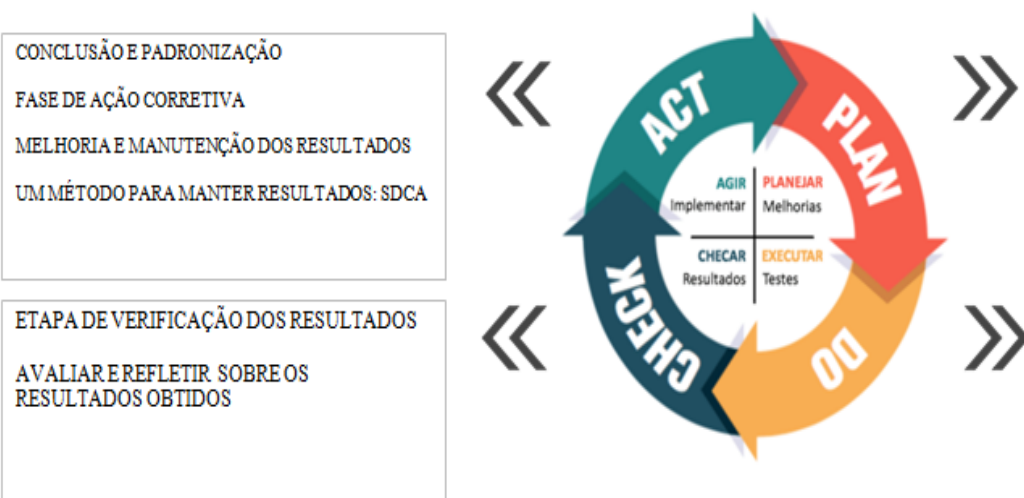

ETAPA DE PLANEJAMENTOÉ A FASE DE
GERENCIAMENTO PARAMAXMMAR
RESUL TADOS EMINIMZARRESOL VER
PROBLEMAS.
-IDENTIFICAR O PROBLEMA
-ANALISAR OPROBLEMA
-ANALISARO PROCESSO
-PLANO DE AÇÃO
EXECUÇÃO DO PLANO DE AÇÃO
NESSA FASE SÃO GERADOS OS RESULTADOS
O OBJETIVO É GARANTIR EXECUÇÃO DA FASE
ANTERIOR

Fonte: Autoria própria

Para visualizar essas informações é só clicar em cima da imagem PDCA que está localizada na aba home. 
Figura 9: Comunicação entre as ferramentas Diagrama de dispersão e Histograma

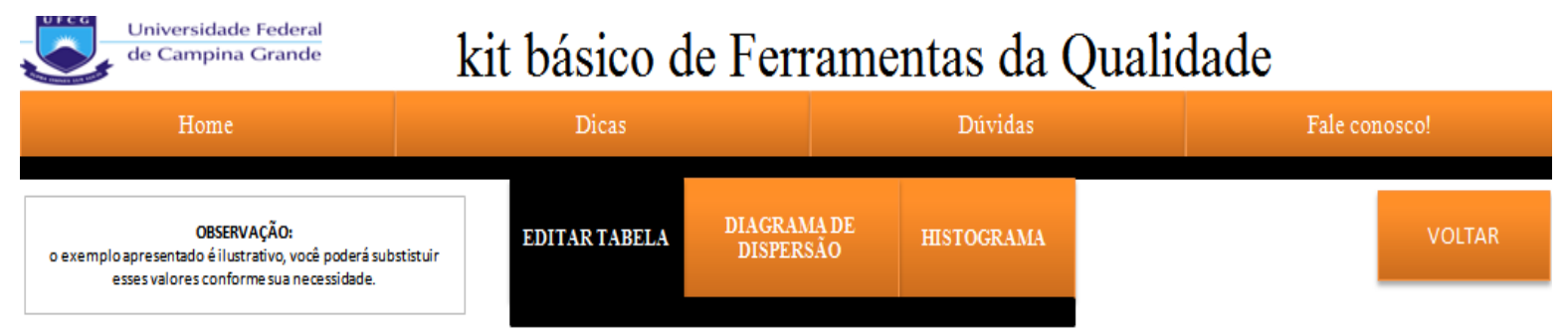

\begin{tabular}{c|c|c|c|}
\hline PRODUTO & MÊS & FATURAMENTO & FÁBRICA \\
\hline A & JANEIRO & 1000,00 & F1 \\
\hline B & FEVEREIRO & 2000,00 & F2 \\
\hline C & MARÇO & 3000,00 & F1 \\
\hline D & ABRIL & 2500,00 & F1 \\
\hline E & MAIO & 5800,00 & F3 \\
\hline F & JUNHO & 9700,00 & F2 \\
\hline G & JULHO & 1500,00 & F2 \\
\hline
\end{tabular}

Fonte: Autoria própria

A comunicação acima apresentada foi feita entre as ferramentas que possuem dados em comum e podem ser relacionadas. Foi adicionado um exemplo para melhor visualização do usuário, para que ele veja a funcionalidade dos gráficos, porém é permitido edições clicando no local e adicionando o valor que deseja. A interface ficou bem interativa, sendo necessário apenas um clique no botão que contém o nome da ferramenta para que seja possível gerar o gráfico.

Figura 10: Comunicação entre as ferramentas teóricas Universidade Federal kit básico de Ferramentas da Qualidade

\begin{tabular}{|c|c|c|c|c|c|}
\hline \multirow[t]{2}{*}{ Home } & \multicolumn{3}{|c|}{ Dicas } & \multicolumn{2}{|l|}{ Dúvidas } \\
\hline & FLUXOGRAMA & 5W2H & SPOR QUESS & $\begin{array}{l}\text { DIAGRAMA DE } \\
\text { ISHIKAWWA }\end{array}$ & $\begin{array}{l}\text { FOLHADE } \\
\text { VERIFICAC̣Ão }\end{array}$ \\
\hline
\end{tabular}

DICA: IR EM INSERIR $>$ FORMAS $>$ FLUXOGRAMA $>$ ESCOLHER A FORMA DESEJADA $>$ COLAR ABAIXO DÚVIDAS: CONSULTAR LEGENDA OU EXEMPLO FLUXOGRAMA

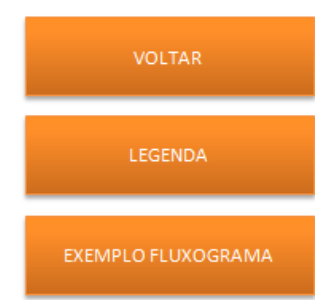

Fonte: Autoria própria

Essa comunicação foi feita apenas com a finalidade de trazer mais funcionalidade para quem for utilizar o programa, pois nele é possível acessar as principais ferramentas teóricas apenas 
com um clique, podendo dessa forma passar de uma ferramenta para outra com mais rapidez e completar as lacunas que possuem mesma resposta de forma mais eficiente.

Após todos os testes, foi constatado que o conjunto de ferramentas aqui proposto e concluído faz jus as expectativas e opera corretamente.

\section{Considerações finais}

Tendo em vista o crescimento acelerado das indústrias e a busca exacerbada por uma melhor qualidade de seus bens e serviços, as ferramentas da qualidade auxiliam justamente no desenvolvimento de processos mais eficientes e com maior aptidão. $\mathrm{O}$ presente artigo trouxe com êxito a elaboração de um programa no Excel que trás todas as ferramentas de qualidade de forma sucinta e prática, utilizando ferramentas relacionadas para que dessa forma possa obter-se um resultado satisfatório e que ajude à organização ou usuário na tomada de decisões e no controle da qualidade.

Logo, foi constatado que o programa tem grande relevância e pode ser utilizado em diversos sistemas de produção, trazendo facilidade e eficiência a quem utilizá-lo.

\section{REFERÊNCIAS BIBLIOGRÁFICAS}

5 POR QUÊS. FM2S Treinamentos. Disponível em 〈https://www.fm2s.com.br/5-porques-como-utilizar/>. Acesso em 29 de Out. de 2019.

AS PRINCIPAIS FERRAMENTAS DE GESTÃO DA QUALIDADE. Sage. Disponível em https://blog.sage.com.br/as-principais-ferramentas-de-gestao-de-qualidade/. Acesso em: 28 de Out. de 2019.

AUNI, Renato. Atingindo objetivos com o PDCA. Rio de Janeiro, 2011. Disponível em: Acesso em: 31 out. 2019.

BEZERRA, Luiz. Diagrama de Ishikawa. 2010. Disponível em. Acesso em: 31 out. 2019.

CARVALHO, M. et al. Gestão da Qualidade - teoria e casos, 2005.

FERRAMENTAS DA QUALIDADE. Siseb. Disponível em: 〈http://siseb.sp.gov.br/arqs/9\%20\%207 ferramentas qualidade.pdf>. Acesso em: 28 de Out. de 2019.

PDCA E SDCA. Blog da Qualidade, 2006. Disponível em: <https://blogdaqualidade.com.br/pdca-e-sdca-vocesabe-a-diferenca/>. Acesso em: 28 de Out. de 2019.

SLACK, N. (2009). Administração da Produção / Nigel. Acesso em: 29 de Out. de 2019.

SLACK, Stuart Chambers, Robert Johnston. Acesso em: 29 de Out. de 2019. 